\title{
ANALISIS PENINGKATAN MINAT BERKUNJUNG KEMBALI PADA WISATAWAN MELALUI CITRA WISATA DAN NILAI BUDAYA (STUDI PADA KOTA KUNINGAN, JAWA BARAT)
}

\author{
Nadya Damayanty Utami ${ }^{1}$ \\ Augusty Tae Ferdinand ${ }^{2}$ \\ 1,2 Master of Management, Faculty of Economics and Business, Diponegoro \\ University
}

\begin{abstract}
ABSTRAK
Penelitian ini memiliki tujuan untuk membangun sebuah model yang akan digunakan untuk menganalisis variabel-variabel yang memiliki gap mengenai citra wisata yang dimiliki daerah wisata terhadap minat berkunjung kembali pada wisatawan, sehingga penelitian ini bertujuan untuk membangun sebuah model yang baru untuk pemasaran pada bidang pariwisata. Penelitian ini mengambil sebanyak 170 responden wisatawan lokal yang berkunjung kembali ke Kuningan Jawa Barat. Alat analisis yang digunakan adalah SEM (Structural Equation Modelling) versi 24. Hasil analisis data untuk keseluruhan model telah memenuhi kriteria Goodness of Fit dengan nilai chi squere $=195.413$, derajat kebebasan $=113$, probabilitas $=$ $0.000, C M I N / D F=1.729, G F I=0.898, A G F I=0.862, T L I=0,973, C F I=0.977$ dan RMSEA $=0.066$. Dengan demikian dapat dikatakan bahwa model penelitian yang diajukan dapat diterima. Dari hasil penelitian diketahui bahwa ada pengaruh yang signifikan antara citra wisata dengan resonansi pelanggan, nilai budaya dengan resonansi pelanggan, nilai budaya dengan ikon daerah wisata, ikon daerah wisata dengan minat berkunjung kembali dan resonansi pelanggan dengan minat berkunjung kembali
\end{abstract}

Kata Kunci: citra wisata, resonansi pelanggan, nilai budaya, ikon daerah wisata, minat berkunjung kembali, wisata jawa barat.

\section{PENDAHULUAN}

Studi mengenai marketing pariwisata menjadi kajian penting pada studi-studi marketing karena pariwisata merupakan suatu industri yang strategis jika dilihat dari bidang ekonomi dan sosial budaya. Industri pariwisata daerah diharapkan dapat 
meningkatkan pendapatan daerah untuk mengembangkan daerah wisata serta meningkatkan pembangunan daerah lebih baik. Persaingan pada sektor pariwisata yang ketat, membuat pemerintah daerah untuk mencari startegi yang tepat dalam memasarkan daerah wisatanya. Menurut Chiu, Zeng et al. (2016), salah satu faktor dalam memasarkan daerah wisata adalah dengan memiliki citra wisata yang baik untuk meningkatkan jumlah kunjungan wisata.

Meningkatkan jumlah pengunjung sangatlah sulit karena ada beberapa faktor yang mempengaruhi minat untuk berkunjung kembali, diantara nya yaitu citra wisata yang baik dimata konsumen sehingga meningkatkan minat berkunjung kembali, sesuai dengan penelitian yang dilakukan Tan and Wu (2016), Chen, Lai et al. (2016), dan Fu, Ye et al. (2016), yaitu citra wisata yang positif berpengaruh terhadap minat berkunjung kembali. Namun ada hasil penelitian yang berbeda mengenai citra wisata dengan minat berkunjung kembali yaitu hasil penelitian dari Kani, Aziz et al. (2017), Souiden, Ladhari et al. (2017), dan Whang, Yong et al. (2015), mengungkapkan bahwa walaupun daerah wisata memiliki citra wisata yang baik, tidak berpengaruh terhadap minat berkunjung kembali.

Dari pemaparan masalah diatas mengenai adanya reseach gap antara citra wisata dengan minat berkunjung kembali, sehingga peneliti mengembangkan masalah penelitian yaitu bagaimana proses citra wisata dan nilai budaya menciptakan nilai yang memberikan pengaruh positif terhadap minat berkunjung kembali. Selain adanya reasech gap pada penelitian ini, peneliti juga menemukan adanya fenomena gap pada jumlah kunjungan wisata Kota Kuningan yaitu jumlah pengunjung wisata Kota Kuningan ini mengalami penurunan jumlah wisatawan nusantaranya di tahun 2016 serta wisatawan mancanegara pada tahun 2013-2016 yang disajikan pada tabel 1.

\section{Tabel 1}

Data Pengunjung Wisata Kota Kuningan

\begin{tabular}{|c|c|c|c|}
\hline & Tahun & Wisatawan Nusantara & $\begin{array}{c}\text { Wisatawan } \\
\text { Mancanegara }\end{array}$ \\
\hline 1 & 2012 & 992.881 & 35 \\
\hline 2 & 2013 & 974.456 & 165 \\
\hline 3 & 2014 & 944.717 & 137 \\
\hline 4 & 2015 & 1.476 .624 & 128 \\
\hline 5 & 2016 & 1.189 .218 & 116 \\
\hline
\end{tabular}

Sumber: BPS Kota Kuningan, 2017

Sesuai dengan teori yang mendasari pada penelitian ini yaitu menggunakan teori consumer utility theory untuk melihat kepuasan pada konsumen ketika berwisata, kepuasan yang didapatkan dari konsumen dalam beriwsata dapat 
berupa citra wisata yang baik sehingga meningkatkan minat berkunjung kembali pada jumlah pengunjung wisata (Kim and Park 2017). Untuk mengatasi hal tersebut, studi ini mencoba untuk melihat citra wisata dan nilai budaya terhadap resonansi pelanggan dan ikon daerah wisata untuk meningkatkan minat berkunjung kembali. Berdasarkan dengan masalah penelitian yang telah dijelaskan maka munculah beberapa pertanyaan mengenai penelitian sebagai berikut: (1) Apakah citra wisata yang dimiliki daerah wisata akan mempengaruhi minat berkunjung kembali?; (2) Apakah citra wisata yang dimiliki daerah wisata berpengaruh untuk meningkatkan resonansi pelanggan?; (3) Apakah nilai budaya yang dimiliki daerah wisata berpengruh untuk meningkatkan resonansi pelanggan?; (4) Apakah nilai budaya yang dimiliki daerah wisata berpengaruh terhadap ikon daerah wisata?; dan (5) Apakah ikon daerah wisata berpengaruh terhadap minat berkunjung kembali?

\section{TELAAH PUSTAKA}

\section{Citra Wisata}

Citra bagi sektor pariwisata merupakan persepsi dari wisatawan terhadap daerah wisata tersebut. Persepsi itu akan muncul ketika wisatawan telah mengunjungi daerah wisata yang dapat mempengaruhi terhadap keputusan berkunjung. Menurut Nassar, Mostafa et al. (2015), citra wisata adalah suatu gambaran daerah wisata atau kesan wisatawan ketika mengunjungi daerah wisata. Konsep citra wisata sangat erat kaitannya dengan destinasi branding yang membangun citra positif untuk membedakan dengan daerah wisata lainnya (Souiden, Ladhari et al.2017). Menurut Foroudi, Akarsu et al. (2018), faktor utama dalam membangun suatu citra wisata adalah membangun suatu daerah wisata dengan ciri khas dari daerah tersebut.

\section{Nilai Budaya}

Menurut Weaver, Kwek et al. (2017), budaya adalah komponen yang meresap pada suatu daerah, kekayaan budaya suatu daerah dapat mempengaruhi pemasaran di bidang pariwisata. Beberapa nilai budaya yang dapat menarik pengunjung di daerah wisata yaitu festival-festival budaya, situs sejarah atau acara yang memotivasi wisatawan untuk berkunjung (Molinillo and Japutra 2017). Keunikan dari salah satu daerah wisata sendiri yaitu memiliki nilai sejarah, etnic budaya dan festival budaya yang unik sehingga wisatawan tertarik untuk berkunjung (Chen, Lai et al. 2016). Menurut (Liu, Li et al. 2018), nilai budaya yang dimiliki seseorang dapat berpengaruh terhadap motivasi berwisata untuk mengunjungi tempat tersebut. 


\section{Resonansi Pelanggan}

Resonansi pelanggan merupakan kegiatan pemasaran yang dilakukan oleh daerah wisata yang membuat wisatawan terus menerus membicarakan hal-hal yang positif maupun hal negatif terhadap daerah wisata yang telah dikunjunginya (Chun, et al. 2014). Ketika wisatawan beresonansi dengan positif, maka wisatawan tersebut akan selalu terbanyang dengan objek wisata yang telah dikunjunginya (Shang, Wu et al. 2017). Objek wisata yang dapat membuat resonansi positif bisa berupa pemandangan alam yang indah sehingga wisatawan tersebut akan terkesan (Benur and Bramwell 2015), serta ikon daerah wisata yang menajadi pesona pada daerah wisata (Warren and Dinnie 2017).

\section{Ikon Daerah Wisata}

Ikon daerah wisata merupakan atribut-atribut khas pada daerah wisata yang melekat pada ingatan masyarakat (Alexander 2008). Atribut-atribut ikonik daerah wisata bisa berupa makanan khas daerah, peninggalan sejarah serta warisan budaya yang berupa monumen atau museum yang ada pada daerah wisata tersebut (Richards and Rotariu 2015) . Menurut Sklair (2010), ikon merupakan ciri khas yang ada pada daerah wisata serta pesona dari daerah wisata. Ikon dari suatu daerah wisata merupakan hal yang penting dalam pemasaran pariwisata sehingga pemerintah selalu mempromosikan wisata ikonik nya (Swanson and Timothy 2012).

\section{Minat Berkunjung Kembali}

Minat berkunjung kembali merupakan perilaku wisatawan dimana wisatawan merespon secara positif terhadap daerah wisata yang pernah dikunjunginya sehingga mendorong untuk kunjungan selanjutnya (Zhang, Wu et al. 2017). Menurut Ting and Thurasamy (2016), daya tarik wisata yang baik dapat menimbulkan kesan yang positif bagi wisatawan sehingga memunculkan minat untuk berkunjung kembali dilain waktu. Pengunjungan kembali pada daerah wisata memiliki pengalaman langsung yang memperkuat untuk berkunjung ke daerah wisata yang pernah dikunjunginya (Shang, Wu et al. 2017).

\section{Citra Wisata terhadap Resonansi Pelanggan}

Hasil penelitian yang dilakukan oleh Duman, Ozbal et al. (2017), wisatawan dapat memiliki penilaian citra wisata yang positif berdasarkan pengalaman berkunjung sehingga akan meningkatkan resonansi pelangggan yang positif yaitu wisatawan akan selalu terbayang akan daerah wisata yang memiliki citra yang positif yang telah dikunjunginya. Resonansi pelanggan adalah sebuah hubungan konsumen dengan tempat wisata atau sejauh mana konsumen merasakan citra wisata tersebut karena saat konsumen sudah merasakan citra wisata yang baik, maka 
akan terbayang di benak konsumen tersebut (Chun, et al. 2014). Oleh karena itu penulis mengajukan hipotesis sebagai berikut:

H1: Semakin positif citra wisata, maka akan semakin positif resonansi yang dimiliki oleh wisatawan.

\section{Nilai Budaya terhadap Resonansi Pelanggan}

Menurut Weaver, Kwek et al. (2017), budaya adalah komponen yang meresap pada suatu daerah, kekayaan budaya suatu daerah dapat mempengaruhi pemasaran di bidang pariwisata. Dalam penelitian dibidang pemasaran parwisata, beberapa penelitan telah menguji hubungan nilai budaya terhadap resonansi pelanggan bahwa nilai budaya yang kuat pada suatu tempat seperti adanya situs bersejarah dapat memberikan resonansi pelanggan yang positif (Duman, Ozbal et al. 2017). Dengan adanya nilai budaya yang kuat pada tempat wisata, maka semakin positif resonansi yang dimiliki oleh wisatawan. Oleh karena itu penulis mengajukan hipotesis sebagai berikut:

H2: Semakin tinggi nilai budaya di suatu tempat wisata, maka semakin positif resonansi yang dimiliki oleh wisatawan.

\section{Nilai Budaya terhadap Ikon Daerah Wisata}

Nilai budaya pada suatu daerah wisata merupakan ciri khas dari tempat wisata tersebut sehingga akan meningkatkan nilai ikonik dari daerah wisata tersebut. Menurut Warren and Dinnie (2017), ikon daerah wisata merupakan identitas dari daerah wisata yang memiliki daya tarik tersendiri sehingga menjadikannya destinasi favorit pada suatu daerah wisata. Nilai budaya pada suatu daerah wisata merupakan ciri khas dari tempat wisata tersebut sehingga akan meningkatkan nilai ikonik dari daerah wisata tersebut. Hal ini sesuai dengan penelitian (Soroka and Lominadze 2011), produk yang memiliki nilai budaya akan meningkatkan nilai ikonik dari daerah wisata tersebut. Oleh karena itu penulis mengajukan hipotesis sebagai berikut:

H3: Semakin tinggi nilai budaya suatu daerah, maka akan meningkatkan nilai ikon daerah wisata.

\section{Ikon Daerah Wisata terhadap Minat Berkunjung Kembali}

Ikon daerah wisata merupakan atribut khas yang melekat pada benak konsumen serta pesona wisata yang ada pada daerah wisata (Sklair 2010). Semakin kuat nilai ikonik dari daerah wisata tersebut maka akan meningkatkan minat berkunjung kembali. sesuai dengan penelitian Pearce, Wu et al. (2015), bahwa objek wisata yang mempunyai nilai ikonik dapat meningkatkan daya tarik bagi wisatawan untuk berkunjung kembali Menurut Foroudi, Akarsu et al. (2018), faktor utama dalam 
meningkatkan pemasaran pada bidang pariwisata adalah membangun suatu daerah wisata dengan ciri khas dari daerah tersebut. Oleh karena itu penulis mengajukan hipotesis sebagai berikut:

H4: Semakin tinggi persepsi ikon daerah wisata, maka akan meningkatkan minat berkunjung kembali

\section{Resonansi Pelanggan terhadap Minat Berkunjung Kembali}

Dengan adanya penelitian dibidang pariwisata yang menguji mengenai resonansi pelanggan terhadap minat berkunjung kembali. Penelitian Shang, Wu et al. (2017), menyatakan bahwa resonansi pelanggan berpengaruh signifikan terhadap minat berkunjung kembali. Menurut An, Lee et al. (2010), ketika wisatawan telah berkunjung, maka wisatawan akan meninjau keputusan mereka sebelumnya mengenai suatu destinasi wisata berdasarkan tingkat kepuasan atau ketidakpuasan mereka untuk berkunjung di lain waktu. Sehingga dengan semakin positif respon dari wisatawan, maka akan meningkatkan minat berkunjung kembali. Oleh karena itu penulis mengajukan hipotesis sebagai berikut:

H5: Semakin positif resonansi pelanggan, maka akan meningkatkan minat berkunjung kembali pada wisatawan

\section{Gambar 1}

\section{Kerangka Pemikiran Teoritis}

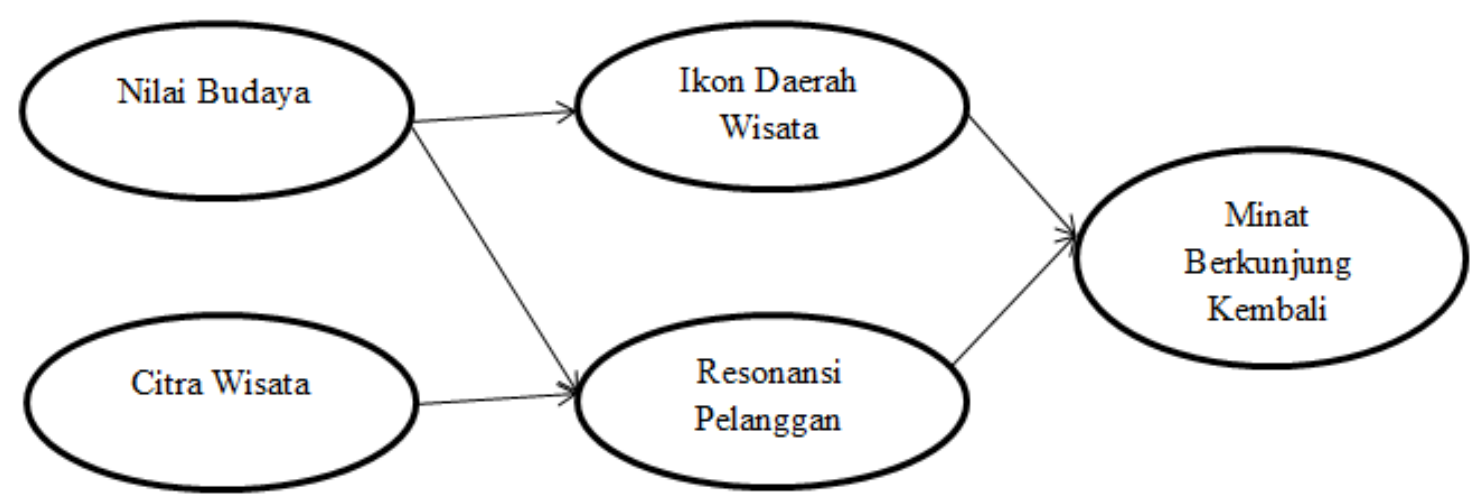

\section{METODE PENELITIAN}

\section{Populasi dan Sampel}

Populasi pada penelitian ini adalah wisatawan lokal yang berkunjung kembali ke Kota Kuningan. Penelitian ini menggunakan metode purposive sampling atau sampel bertujuan secara subyektif. Pemilihan sampel dilakukan terhadap suatu kelompok sasaran tertentu yang memenuhi kriteria peneliti serta mampu 
memberikan informasi yang dibutuhkan oleh peneliti (Ferdinand, 2014). Penelitian ini mengambil 170 orang responden yang merupakan wisatawan lokal yang berkunjung kembal ke Kuningan.

\section{Indikator Variabel}

Variabel citra wisata dibangun oleh lima model indikator penjelasan yaitu: pemandangan yang indah, cuaca yang baik (Lee and Lockshin 2011), infrastrutur yang baik, kondisi sosial yang baik, dan akomodasi yang mudah (Gomez, Lopez et al. 2015). Variabel nilai budaya dibangun oleh 5 model indikator penjelasan yaitu: warisan budaya, nilai sejarah (Iniesta-Bonillo, Sánchez-Fernández et al. 2016), festival budaya, pusat kebudayaan (Kladou and Kehagias 2014), dan makanan tradisional (Sato, Kim et al. 2016). Variabel ikon daerah wisata dibangun oleh tiga model indikator penjelasan yaitu: atribut khas wisata, identitas wisata dan keunikan daerah wisata (Lin and Mao 2015). Variabel minat berkunjung kembali dibangun oleh tiga indikator yaitu: berkunjung dimasa depan, prioritas wisata (Cong 2016), kunjungan yang sering (Sato, Kim et al. 2016).

\section{Metode Analisis}

Penelitian ini merupakan penelitian kuantitatif dengan menggunakan analisis SEM dan software AMOS 24. Kuesioner sendiri merupakan teknik perolehan informasi dengan cara mengajukan beberapa pertanyaan atau pernyataan yang terkait penelitian yang dilakukan kepada responden untuk dicari jawabannya. Pertanyaan atau pernyataan diajukan sesuai dengan indikator yang ada dalam penelitian. Dalam penelitian ini terdapat 19 indikator yang menjadi data primer, terdiri dari beberapa variabel yakni citra wisata ( 5 data), nilai budaya ( 5 data), resonansi pelanggan ( 3 data), ikon daerah wisata ( 3 data) dan minat berkunjung kembali ( 3 data). Pengukuran menggunakan interval skala dari 0 s/d 10 semakin ke angka 10 maka semakin setuju.

\section{ANALISIS DATA DAN PEMBAHASAN Analisis Data}

Teknik analisa yang digunakan dalam penelitian ini adalah dengan mengggunakan teknik Structural Equation Modelling (SEM). Berikut ini adalah tahap-tahap yang telah dilakukan dalam analisis SEM:Pertama, uji kelayakan model dengan menggunakan kriteria dasar dari SEM seperti tingkat signifikasi uji chiSquare full model memiliki nilai sebesar 195,413, angka tersebut diatas chi Square tabel dengan derajat kebebasan 113 ditingkat signifikan 5\% sebesar 138,8113 . Nilai probabilitas $=0,000 \mathrm{RMSEA}=0.66, \mathrm{GFI}=0,898, \mathrm{AGFI}=0,862, \mathrm{TLI}=$ 
0,973 CMIN/DF =1,729 dan CFI = 0,977 Dapat dikatakan bahwa hasil tersebut menunjukan bahwa uji kelayakan model ini sudah memenuhi kriteria model fit (Goodness of-Fit Indices).

Kedua, pengujian hipotesis untuk hubungan antar variabel dengan menggunakan kriteria CR. Menurut Ferdinad (2014), syarat CR yang ditentukan yaitu $\geq 2,00$. Hasil analisis data menunjukan hubungan yang signifikan positif antar variabel serta hasil dari pengujian hipotesis dapat dilihat pada tabel 2, yaitu hipotesis 1 antara citra wisata dengan resonansi pelanggan memberikan nilai CR: 8,960 dan P: 0,000 , oleh karena itu hipotesis pertama diterima. Hasil untuk hipotesis 2 yaitu nilai budaya dengan resonansi pelanggan $C R: 8,056$ dan P: 0,000 , oleh karena itu hipotesis kedua diterima. Hasil dari hipotesis 3 yaitu nilai budaya dengan ikon daerah wisata CR: 11,955 dan P: 0,000 oleh karena itu hipotesis ketiga diterima. Hasil dari hipotesis 4 yaitu ikon daerah wisata dengan minat berkunjung kembali CR: 8,841 dan P: 0,000 oleh karena itu hipotesis keempat diterima Selanjutnya, hipotesis 5 yaitu resonansi pelanggan dengan minat berkunjung kembali CR: 7,917 dan P: 0,000, oleh karena itu hipotesis kelima diterima.

Tabel 2

Pengujian Hipotesis

\begin{tabular}{|c|c|c|}
\hline & Std.Est & $\begin{array}{c}\text { Hasil Uji (indeks CR } \\
\text { dan P) }\end{array}$ \\
\hline H1 & 0,540 & $\begin{array}{c}\text { Diterima }(\mathrm{CR}: 8,960 \text { dan } \\
\text { P: } 0,000)\end{array}$ \\
\hline H2 & 0,572 & $\begin{array}{c}\text { Diterima }(\mathrm{CR}: 8,056 \text { dan } \\
\text { P: } 0,000)\end{array}$ \\
\hline H3 & 0,762 & $\begin{array}{c}\text { Diterima }(\mathrm{CR}: 11,955 \text { dan } \\
\text { P: } 0,000)\end{array}$ \\
\hline H4 & 0,602 & $\begin{array}{c}\text { Diterima }(\mathrm{CR}: 8,841 \text { dan } \\
\text { P: } 0,000)\end{array}$ \\
\hline H5 & 0,508 & $\begin{array}{c}\text { Diterima }(\mathrm{CR}: 7,917 \text { dan } \\
\text { P: } 0,000)\end{array}$ \\
\hline
\end{tabular}

\section{Pembahasan}

Berdasarkan hasil penelitian ini, variabel citra wisata memberikan kontribusi dalam mempengaruhi resonansi pelanggan. Hal tersebut bisa dilihat dari besaran pengaruhnya $(0,544)$ dan taraf signifikansinya (CR 8,960; P 0,000). Dengan begitu untuk meningkatkan pelanggan, maka pengelola daerah wisata perlu untuk meningkatkan citra wisata yang ada pada daerah wisata seperti merawat wisata 
alam, budaya dan sejarahnya yang sudah ada, pengelola pariwisata perlu juga mengembangkan objek wisata seperti menambah tempat-tempat untuk berfoto yang menarik dan selalu diperbaruai agar tidak membosankan, memperbaiki infrastruktur di berbagai lokasi wisata agar akses mudah, serta menambah akomodasi untuk menuju ke tempat wisata yang sulit untuk dijaungkau. Dengan meningkatkan citra wisata yang positif pada wisata Kuningan, maka akan membuat pengunjung tersebut terkesan dengan wisata yang ada di Kuningan sehingga dapat meningkatkan jumlah pelanggan.

Hasil penelitian juga membuktikan bahwa nilai budaya berpengaruh secara langsung terhadap resonansi pelanggan. Hal tersebut dapat dilihat dari besaran pengaruhnya yaitu $(0,469)$ dengan taraf signifikan (CR:8,056 dan $P: 0,000)$. Dengan begitu, untuk meningkatkan jumlah wisatawan, maka pengelola daerah wisata Kuningan perlu untuk menjaga nilai budaya yang ada pada daerah wisata seperti merawat daerah wisata yang berhubungan dengan sejarah dan budaya serta mempertahakan nilai-nilai budaya yang sudah ada untuk meningkatkan jumlah pelanggan. Hasil penelitian membuktikan adanya pengaruh yang besar antara nilai budaya terhadap ikon daerah wisata dengan nilai 0,761 dan taraf signifikannya yaitu (CR:11,955 dan P: 0,000), hal ini menunjukan bahwa secara langsung nilai budaya berpengaruh psoitif terhadap ikon daerah wisata. Dengan meningkatkan nilai-nilai budaya yang ada pada Kota Kuningan, maka akan meningkatkan ikon daerah wisata tersebut. Seperti, wisata Cibulan yang memiliki nilai budaya di Kota Kuningan, sehingga menjadi destinasi favorit dan meningkatkan nilai ikonik wisata tersebut.

Hasil penelitian membuktikan bahwa, ikon daerah wisata dengan minat berkunjung kembali memiliki pengaruh langsung dan memiiliki nilai pengaruh yang positif yaitu $(0,513)$ dengan taraf signifikan (CR:8,841 dan P: 0,000). Dengan hasil yang didapatkan, ikon daerah wisata dapat berpengaruh secara langsung terhadap minat berkunjung kembali, dengan semakin tingginya nilai ikonik yang ada pada daerah wisata tersebut, maka akan meningkatkan jumlah kunjungan karena nilai ikonik merupakan ciri khas dari suatu tempat wisata yang membedakannya dengan tempat wisata lain. Berbeda dengan variabel resonansi pelanggan yang memiliki pengaruh lebih besar terhadap minat berkunjung kembali yaitu $(0,597)$ dengan nilai signifikan yaitu (CR:7,917 dan P: 0,000). Dengan meningkatnya wisatawan, maka akan meningkatkan minat berkunjung kembali karena ketika wisatawan sudah terkesan dengan apa yang didapatkan dari daerah wisata tersebut maka akan meningkatkan minat berkunjung kembali.

Hasil statistik citra wisata memberikan pengaruh tidak langsung terhadap minat berkunjung kembali sebesar 0,315 . Selain itu nilai budaya juga secara tidak langsung memiliki pengaruh positif dengan nilai yang tinggi terhadap minat 
berkunjung kembali sebesar 0,738. Hal ini menandakan bahwa secara tidak langsung dengan meningkatkan citra wisata serta nilai budaya yang ada pada daerah wisata dapat meningaktkan minat berkunjung kembali, seperti memelihara objek wisata alam, sejarah dan budaya yang ada di Kuningan.

Berbagai macam tanda pengunjung ingin berkunjung kembali pada daerah wisata yaitu dengan membuat rencana dengan mencari hari atau tanggal yang sesuai, merekomendasikan tempat wisata tersebut kepada teman atau keluarganya serta menjadikan wisata tersebut adalah daerah wisata yang harus selalu dikunjunginya atau daerah wisata prioritasnya. Hal tersebut muncul salah satunya karena resonansi pelanggan yang positif, sehingga hal tersebut bisa menjadikan pengunjung ingin berkunjung kembali ketempat wisata tersebut.

\section{KESIMPULAN DAN SARAN}

\section{Kesimpulan}

Dari hasil penelitian ini, pengelola pariwisata yang ada di Kota Kuningan perlu memperhatikan citra wisata serta nilai budaya yang mampu menciptakan keunikan yang dapat membedakan dengan tempat wisata lainnya serta mempromosikan nilai ikonik dari pariwisata tersebut sehingga diharapkan bisa meningkatkan minat berkunjung kembali para wisatawan. Selain itu pengelola juga perlu mengembagkan tempat-tempat yang bisa membawa para berkunjung untuk mudah dan nyaman dalam beraktivitas disana. Dari berbagai hal tersebut, diharapkan dapat meningkatkan jumlah wisatawan yang berdampak pada minat berkunjung kembali.

Hasil penelitian yang telah dilakukan, memberikan saran kepada pengelola wisata Kuningan yaitu sebaiknya pihak pengelola menambah spot untuk berfoto karena wisatawan kaum milenial lebih senang untuk mengabadikan moment saat berwisata, menambah serta mengembangkan objek wisata yang ada dekat dengan alam seperti membuat cafe dengan pemandangan alam yang indah sehingga meningkatkan minat untuk berkunjung ulang, mempromosikan lagi wisata sejarah dan budaya yang ada di Kuningan, menyambut wisatawan dengan budaya yang ada di Kuningan, mempromosikan makanan tradisional yang ada di Kuningan agar produk lokal Kuningan lebih di kenal sehingga mampu untuk meningkatkan minat berkunjung ulang pada wisatawan serta akses untuk menuju tempat wisata dapat dipermudah, pengelola wisata perlu mempromosikan lagi apa yang menjadi ikon daerah wisata Kuningan untuk membedakan wisata Kuningan dengan wisata lainnya mengembangkan lagi objek wisata terutama wisata alam untuk meningkatkan minat berkunjung ulang. 


\section{Saran}

Penelitian ini tidak dilakukan pada seluruh wisata di Kuningan namun hanya dilakukan pada beberapa objek wisata yang ada di Kuningan. Keterbatasan penelitian yaitu berfokus pada satu daerah wisata yaitu Kuningan Jawa Barat.Serta masih kurangnya indikator-indikator untuk meneliti beberapa aspek lagi mengenai pariwisata di Kuningan. Penelitian yang akan datang harus membandingkan beberapa daerah wisata untuk membuktikan adanya reseach gap. Responden untuk penelitian yang akan datang diharapkan responden dari mancanegara untuk mengetahui persepsi mengenai pariwisata yang ada di Indonesia. Selain itu, diharapkan adanya variabel baru untuk mengembangkan model yang baru pada pemasaran di bidang pariwisata.

\section{REFERENSI}

Alexander, J. C. (2008). "Iconic Experience in Art and Life." Theory, Culture \& Society 25(5): 1-19.

An, M., et al. (2010). "Risk factors at the travel destination: their impact on air travel satisfaction and repurchase intention." Service Business 4(2): 155-166.

Benur, A. M. and B. Bramwell (2015). "Tourism product development and product diversification in destinations." Tourism Management 50: 213-224.

Chen, C.-C., et al. (2016). "Tourism between divided nations: An examination of stereotyping on Citra Wisata." Tourism Management 55: 25-36.

Chiu, W., et al. (2016). "The influence of Citra Wisata and tourist satisfaction on tourist loyalty: a case study of Chinese tourists in Korea." International Journal of Culture, Tourism and Hospitality Research 10(2): 223-234.

Cong, L. C. (2016). "A formative model of the relationship between destination quality, tourist satisfaction and intentional loyalty: An empirical test in Vietnam." Journal of Hospitality and Tourism Management 26: 50-62.

Duman, T., et al. (2017). "The role of affective factors on brand resonance: Measuring customer-based brand equity for the Sarajevo brand." Journal of Destination Marketing \& Management.

Ferdinand, A. T. (2014). Metode Penelitian Manajemen Pedoman Penelitian Untuk Penulisan Skripsi Tesis Dan Disertasi Ilmu Manajemen. Semarang, Indonesia, Badan Penerbit Universitas Diponegoro.

Foroudi, P., et al. (2018). "PROMISING THE DREAM: Changing Citra Wisata of London through the effect of website place." Journal of Business Research 83: 97-110. 
Fu, H., et al. (2016). "Reality TV, audience travel intentions, and Citra Wisata."

Gomez, M., et al. (2015). "A model of tourism destination brand equity: The case of wine tourism destinations in Spain."

Iniesta-Bonillo, M. A., et al. (2016). "Sustainability, value, and satisfaction: Model testing and cross-validation in tourist destinations." Journal of Business Research 69(11): 5002-5007.

Kani, Y., et al. (2017). "Antecedents and outcomes of Citra Wisata of Malaysia." Journal of Hospitality and Tourism Management 32: 89-98.

Kim, D. and B.-J. Park (2017). "The moderating role of context in the effects of choice attributes on hotel choice: A discrete choice experiment." Tourism Management 63: 439-451.

Kladou, S. and J. Kehagias (2014). "Assessing destination brand equity: An integrated approach." Journal of Destination Marketing \& Management 3(1): 210.

Lee, R. and L. Lockshin (2011). "Halo effects of tourists' Citra Wisata on domestic product perceptions." Australasian Marketing Journal (AMJ) 19(1): 7-13.

Lin, L. and P.-C. Mao (2015). "Food for memories and culture - A content analysis study of food specialties and souvenirs." Journal of Hospitality and Tourism Management 22: 19-29.

Liu, H., et al. (2018). "Perceived cultural distance and international destination choice: The role of destination familiarity, geographic distance, and cultural motivation." Journal of Destination Marketing \& Management.

Alexander, J. C. (2008). "Iconic Experience in Art and Life." Theory, Culture \& Society 25(5): 1-19.

An, M., et al. (2010). "Risk factors at the travel destination: their impact on air travel satisfaction and repurchase intention." Service Business 4(2): 155-166.

Benur, A. M. and B. Bramwell (2015). "Tourism product development and product diversification in destinations." Tourism Management 50: 213-224.

Chen, C.-C., et al. (2016). "Tourism between divided nations: An examination of stereotyping on Citra Wisata." Tourism Management 55: 25-36.

Chiu, W., et al. (2016). "The influence of Citra Wisata and tourist satisfaction on tourist loyalty: a case study of Chinese tourists in Korea." International Journal of Culture, Tourism and Hospitality Research 10(2): 223-234. 
Cong, L. C. (2016). "A formative model of the relationship between destination quality, tourist satisfaction and intentional loyalty: An empirical test in Vietnam." Journal of Hospitality and Tourism Management 26: 50-62.

Duman, T., et al. (2017). "The role of affective factors on brand resonance: Measuring customer-based brand equity for the Sarajevo brand." Journal of Destination Marketing \& Management.

Ferdinand, A. T. (2014). Metode Penelitian Manajemen Pedoman Penelitian Untuk Penulisan Skripsi Tesis Dan Disertasi Ilmu Manajemen. Semarang, Indonesia, Badan Penerbit Universitas Diponegoro.

Foroudi, P., et al. (2018). "PROMISING THE DREAM: Changing Citra Wisata of London through the effect of website place." Journal of Business Research 83: 97-110.

Fu, H., et al. (2016). "Reality TV, audience travel intentions, and Citra Wisata."

Gomez, M., et al. (2015). "A model of tourism destination brand equity: The case of wine tourism destinations in Spain."

Iniesta-Bonillo, M. A., et al. (2016). "Sustainability, value, and satisfaction: Model testing and cross-validation in tourist destinations." Journal of Business Research 69(11): 5002-5007.

Kani, Y., et al. (2017). "Antecedents and outcomes of Citra Wisata of Malaysia." Journal of Hospitality and Tourism Management 32: 89-98.

Kim, D. and B.-J. Park (2017). "The moderating role of context in the effects of choice attributes on hotel choice: A discrete choice experiment." Tourism Management 63: 439-451.

Kladou, S. and J. Kehagias (2014). "Assessing destination brand equity: An integrated approach." Journal of Destination Marketing \& Management 3(1): 210.

Lee, R. and L. Lockshin (2011). "Halo effects of tourists' Citra Wisata on domestic product perceptions." Australasian Marketing Journal (AMJ) 19(1): 7-13.

Lin, L. and P.-C. Mao (2015). "Food for memories and culture - A content analysis study of food specialties and souvenirs." Journal of Hospitality and Tourism Management 22: 19-29.

Liu, H., et al. (2018). "Perceived cultural distance and international destination choice: The role of destination familiarity, geographic distance, and cultural motivation." Journal of Destination Marketing \& Management. 
Molinillo, S. and A. Japutra (2017). "Factors influencing domestic tourist attendance at cultural attractions in Andalusia, Spain." Journal of Destination Marketing \& Management 6(4): 456-464.

Nassar, M. A., et al. (2015). "Factors influencing travel to Islamic destinations: an empirical analysis of Kuwaiti nationals." International Journal of Culture, Tourism and Hospitality Research 9(1): 36-53.

Pearce, P. L., et al. (2015). "The spectacular and the mundane: Chinese tourists' online representations of an iconic landscape journey." Journal of Destination Marketing \& Management 4(1): 24-35.

Richards, G. and I. Rotariu (2015). "Developing the eventful city in Sibiu, Romania." International Journal of Tourism Cities 1(2): 89-102.

Sato, S., et al. (2016). "Adventure tourism motivation and destination loyalty: A comparison of decision and non-decision makers." Journal of Destination Marketing \& Management.

Shang, S. S. C., et al. (2017). "Generating consumer resonance for purchase intention on social network sites." Computers in Human Behavior 69: 18-28.

Sklair, L. (2010). "Iconic Architecture and the Culture-ideology of Consumerism." Theory, Culture \& Society 27(5): 135-159.

Soroka, E. and T. Lominadze (2011). "Branding destination through iconic product."

Souiden, N., et al. (2017). "Destination personality and Citra Wisata." Journal of Hospitality and Tourism Management 32: 54-70.

Swanson, K. K. and D. J. Timothy (2012). "Souvenirs: Icons of meaning, commercialization and commoditization." Tourism Management 33(3): 489-499.

Tan, W.-K. and C.-E. Wu (2016). "An investigation of the relationships among destination familiarity, Citra Wisata and future visit intention." Journal of Destination Marketing \& Management 5(3): 214-226.

Warren, G. and K. Dinnie (2017). "Exploring the dimensions of place branding: an application of the ICON model to the branding of Toronto." International Journal of Tourism Cities 3(1): 56-68.

Weaver, D. B., et al. (2017). "Cultural connectedness and visitor segmentation in diaspora Chinese tourism." Tourism Management 63: 302-314.

Whang, H., et al. (2015). "Pop culture, Citra Wisatas, and visit intentions: Theory and research on travel motivations of Chinese and Russian tourists." Journal of Business Research 
Zhang, H., et al. (2017). "A model of perceived image, memorable tourism experiences and minat berkunjung kembali." Journal of Destination Marketing \& Management. 